\title{
Alfabetização científica, criança e espaços de educação não formal: diálogos possíveis
}

\author{
Amanda Cristina Teagno Lopes Marques ${ }^{1}$ \\ Martha Marandino²
}

\section{Resumo}

Este artigo tem por objetivo discutir, do ponto de vista teórico, as possíveis interações entre alfabetização científica (AC), criança e educação não formal (ENF). A questão da pesquisa pode ser sintetizada na seguinte formulação: Do ponto de vista conceitual, quais inter-relações podem ser estabelecidas entre alfabetização científica, criança e educação não formal? Para tal, realizou-se estudo exploratório a partir de pesquisa bibliográfica sobre o tema. Defende-se a alfabetização científica como processo que ocorre dentro e fora da escola e que implica: i) a promoção de diálogos e aproximações entre a cultura experiencial dos indivíduos e a cultura científıca; ii) a apropriação de saberes relacionados a termos e conceitos científicos, à natureza da ciência, às relações entre ciência, tecnologia e sociedade; iii) a promoção de condições necessárias à realização de leituras críticas da realidade, à participação no debate público, à tomada de decisão responsável, à intervenção social em uma perspectiva emancipadora e de inclusão social. Na discussão, aponta-se para a necessidade de integrar a criança às ações desenvolvidas em espaços de ENF que visem à ampliação das possibilidades de AC da população, entendendo-a como processo, objetivo educativo e direito. 0 direito da criança à AC não pode representar a negação do direito à vivência da(s) infância(s); a aproximação à cultura científica não significa a supressão das culturas da(s) infância(s), mas a ampliação destas, o que pode ser potencializado via ENF.

\section{Palavras-chave}

Alfabetização científica - Criança - Educação não formal.

\section{Scientific literacy, child and non-formal education settings: possible dialogues}

\section{Abstract}

This article aims to discuss, from a theoretical point of view, the possible interactions between scientific literacy (SL), child and non-formal education (NFE). The research question can be summarized in the following formulation: From the conceptual point of

1- Instituto Federal de Educação, Ciência e Tecnologia de São Paulo, São Paulo, SP, Brasil. Contato: amandamarques@ifsp.edu.br

2- Faculdade de Educação, Universidade de São Paulo, São Paulo, SP, Brasil. Contato: marmaran@usp.br 
view, what interrelations can be established between scientific literacy, the child and nonformal education? For that, an exploratory study was carried out based on bibliographic research. Scientific literacy is advocated as a process that takes place inside and outside the school and implies: i) conducting dialogues and approaches between the individual's experiential culture and scientific culture; ii) appropriating knowledge related to scientific terms and concepts, nature of science, and relations between science, technology and society; iii) fostering the necessary conditions for critical analysis of reality, participation in the public debate, responsible decision-making, and social intervention in an emancipation and social inclusion perspective. The discussion points out the need to integrate the child to SL actions developed in NFE settings, as SL is seen as a process, an educational objective and a right. The children's right to SL does not mean declining their right to enjoy their childhood(s); approaching them to scientific culture does not mean suppressing childhood('s) culture(s), but expanding them, something that can be enhanced through IE.

\section{Keywords}

Scientific literacy - Child - Non-formal education.

\section{Introdução}

No contexto atual, discussões sobre alfabetização científica (AC) têm ocupado lugar de destaque em pesquisas no campo da educação em ciências. Defende-se a ideia de que cabe à escola e à sociedade promover condições de acesso e apropriação do conhecimento científico à população de modo a possibilitar a efetiva participação nos processos de tomada de decisão (BYBEE, 1995; ROBERTS, 2007; KRASILCHIK; MARANDINO, 2007; SANTOS, 2007; CACHAPUZ et al., 2011), superando práticas de acúmulo de informações com função propedêutica, exclusivamente com vistas à preparação para a escolaridade futura ou à formação de futuros cientistas. A proposta reveste-se, também, de um viés democratizante, visando à efetiva inclusão social da população via participação e engajamento no debate público sobre questões relacionadas à ciência, à tecnologia e à sociedade, o que demanda cidadãos não apenas conhecedores da ciência - entendida como produção humana, histórica e socialmente contextualizada, permeada por valores, interesses e perspectivas muitas vezes conflitantes, não neutra, portanto -, mas também das relações que se estabelecem entre os conhecimentos científicos e as práticas sociais (LEWENSTEIN; BROSSARD, 2006; DAZA-CAICED0, 2013).

Ainda em relação ao que podemos denominar paradigma atual nas discussões sobre o ensino de ciências, destaque deve ser dado à compreensão de que o processo de alfabetização científica - trata-se de um processo, vale ressaltar - é contínuo e permanente, transcendendo a instituição escolar. Isso significa dizer que a alfabetização científica ocorre em outras instâncias para além da escola (JENKINS, 1994), ainda que esta tenha 
um papel imprescindível - e insubstituível, a nosso ver - nesse processo; museus, mídia impressa ou audiovisual, entre outras instâncias, "devem se colocar como parceiros nessa empreitada de socializar o conhecimento científico de forma crítica para a população" (KRASILCHIK; MARANDINO, 2007, p. 17). Também Henriksen e Froyland (2000) destacam a contribuição dos museus na promoção da AC da população em geral, indicando-a como objetivo a ser perseguido pelas instituições.

Nesse contexto, propusemo-nos a indagar em que medida é possível - e necessário incluir a criança nas discussões e nas práticas de alfabetização científica, considerando-a no contexto da educação não formal. Partimos da concepção de criança como agente, sujeito produtor de cultura, ser histórico cujo modo de ser e estar no mundo é influenciado pelas representações que se estabelecem acerca da infância - e suas potencialidades ou, de outra parte, incompletudes - e das condições concretas que perpassam sua(s) infância(s), conceito este compreendido em uma perspectiva geracional (CORSARO, 2011; JENKS, 2002; QVORTRUP, 1994; SARMENTO, 2005). Entendendo a alfabetização científica como processo e a criança como sujeito inserido em um contexto social, com possibilidade de agência e cidadania (definidas em termos específicos, diferentes do que é esperado do adulto), é válido pensar que a criança pode ser alfabetizada cientificamente? 0 que esperar desse processo?

Dando prosseguimento às discussões e considerando a necessidade de que espaços de educação não formal (ENF) também assumam o compromisso com a promoção da alfabetização científica da população, questionamo-nos acerca da função desses espaços no que tange à alfabetização científica de crianças. Qual pode ser o papel desempenhado pela educação não formal na promoção da alfabetização científica de crianças pequenas (de 0 a 5 anos)?

À luz do exposto, sintetizamos a questão que norteia o presente artigo na seguinte formulação: Do ponto de vista conceitual, quais inter-relações podem ser estabelecidas entre alfabetização científica, criança e educação não formal? Da questão central, desdobram-se outras, a saber: Quando começa o processo de alfabetização científica? Podemos incluir a criança pequena - considerada, neste artigo, a criança de 0 a 5 anos - nesse processo? Quais implicações decorrem da consideração da criança como sujeito do processo de alfabetização científica? Podemos pensar na educação não formal como espaço para a alfabetização científıca? Nosso objetivo geral é discutir, do ponto de vista teórico, as possíveis interações entre alfabetização científica, criança e educação não formal. Como objetivos específicos, destacamos: a) refletir sobre a possibilidade de inserir a criança pequena (de 0 a 5 anos) como sujeito do processo de alfabetização científica, considerando suas especificidades; b) refletir sobre as contribuições de espaços não formais de educação para o processo de alfabetização científica de crianças.

Do ponto de vista metodológico, realizamos estudo exploratório (GIL, 2002) a partir de pesquisa bibliográfica sobre o tema, apresentando revisão com vistas a construir argumentos em defesa da inclusão da criança pequena nas discussões sobre AC. Em se tratando de estudo exploratório, objetivamos proporcionar familiaridade com o problema e aprimorar ideias e propostas, ampliando a reflexão (GIL, 2002). A pesquisa bibliográfica compõe o estudo exploratório realizado, tendo sido "desenvolvida com base em material já 
elaborado, constituído principalmente de livros e artigos científicos" (GIL, 2002, p. 44). As fontes bibliográficas utilizadas foram artigos de periódicos e livros, abrangendo estudos clássicos sobre o tema e estudos mais atualizados. As bases de dados Scielo e Portal de Periódicos Capes foram empregadas na busca e na localização de artigos, além da consulta aos sítios de revistas classificadas com Qualis A nas áreas de avaliação Educação e Ensino. Para a busca, palavras-chave foram utilizadas para cercar a temática focalizada, como descrito mais à frente.

0 presente artigo está estruturado em três seções. Na primeira, discutimos os significados da alfabetização científica, indicando a perspectiva por nós assumida. $\mathrm{Na}$ sequência, tecemos reflexões sobre as relações entre alfabetização científica e criança. Na terceira seção, apresentamos o conceito de educação não formal para, nas considerações finais, procurar responder à questão central proposta nesta introdução.

\section{Sentidos e significados do termo alfabetização científica}

Laugksch (2000) alerta que o conceito de scientific literacy é bastante difuso, apresentando diversos significados e interpretações que expressam visões sobre o que o público deveria saber sobre ciência e sobre quem é esse público. Para o autor, mostra-se impraticável construir uma definição absoluta do termo, uma vez que a concepção de alfabetização científica depende do contexto para o qual se destina operar; trata-se, portanto, de um conceito social e historicamente situado. Nesse sentido, faz-se necessário que os pesquisadores explicitem seu posicionamento ao discutir o conceito, indicando a compreensão em que fundamentam suas análises.

À luz das recomendações de Laugksch (2000), discutiremos nesta seção o conceito de alfabetização científica para, na sequência, dialogar sobre sua pertinência ao tratarmos da educação de crianças pequenas. Cabe ressaltar que Santos (2007) defende a utilização do termo letramento científico em detrimento de alfabetização científica, buscando "enfatizar a função social da educação científıca contrapondo-se ao restrito significado de alfabetização escolar” (SANTOS, 2007, p. 479). Para o autor, o termo alfabetização cientifica pode sugerir apenas o domínio da linguagem científica, enquanto a perspectiva de letramento implica a prática social e inclui a participação ativa do indivíduo na sociedade. A denominação letramento foi também assumida no levantamento realizado pelo Instituto Abramundo (2014).

A partir da perspectiva de Paulo Freire, no entanto, podemos considerar o conceito de alfabetização de maneira ampliada, levando em conta a necessária compreensão crítica do ato de ler não apenas a palavra, mas também, e essencialmente, o mundo: "A leitura do mundo precede a leitura da palavra, daí que a posterior leitura desta não possa prescindir da continuidade da leitura daquele. Linguagem e realidade se prendem dinamicamente" (FREIRE, 1988, p. 12). Isto porque "a memorização mecânica da descrição do objeto não se constitui em conhecimento do objeto” (FREIRE, 1988, p. 17); conhecer implica estabelecer relações entre texto e contexto, palavra e mundo, processo dialógico no qual a curiosidade ingênua vai sendo superada rumo à curiosidade epistemológica, "crítica, insatisfeita, indócil" (FREIRE, 1996, p. 32), o que permite a assunção do sujeito, ser pensante, transformador, 
criador, ser histórico e social. Dos argumentos expostos, decorre nossa opção pelo termo alfabetização científica, cujo significado será discutido a seguir.

Os debates sobre a expressão alfabetização científica nos Estados Unidos da América (EUA) tiveram início no final da década de 1950 (LAUGKSCH, 2000), no contexto da Guerra Fria e da corrida espacial. 0 período entre o final de 1970 e o início de 1980 foi permeado pelo aparecimento de variadas definições e interpretações, sendo marcado pela emergência do Japão e de outros países da costa do Pacífico como potências econômicas, assim como pelo sentimento de declínio da competitividade econômica dos EUA. Diante de tal cenário, ciência e tecnologia passam a ser vistas como fundamentais ao progresso econômico.

Miller (1998) considera a alfabetização científica um conceito multidimensional, que envolve três aspectos: 1. A apropriação de termos e conceitos científicos que permitam a leitura e a compreensão de visões em disputa divulgadas pela mídia; 2.0 entendimento da natureza da ciência e do processo de pesquisa; 3. Alguma compreensão sobre o impacto da ciência e da tecnologia sobre os indivíduos e a sociedade. Na mesma direção, Garfield (1988) considera que o indivíduo cientificamente alfabetizado compreende a natureza e os limites da ciência, domina o conhecimento conceitual básico nas principais disciplinas e percebe as implicações sociais, culturais e éticas da ciência e da tecnologia.

A nosso ver, o conceito apontado por Miller (1998) e Garfield (1988) restringe-se ao domínio das ferramentas, em uma compreensão ampliada da ciência, sem dúvida, mas mantendo o indivíduo como espectador de disputas e decisões que ocorrem no contexto social. Não há menção à participação social, ainda que os elementos por eles apontados sejam condições necessárias àquela - necessárias, mas não suficientes.

Fourez (2003), analisando o que é por ele denominado "crise no ensino de ciências", questiona o papel da escola: formar cidadãos ou formar especialistas? Para o autor, a perspectiva de alfabetização científica expressa-se em termos de finalidades humanistas (capacidade de situar-se em um universo técnico-científico e utilizar as ciências para decodificar seu mundo), sociais (diminuição das desigualdades produzidas pela falta de compreensão das tecno-ciências, ampliando as possibilidades de engajamento nos debates atuais) e econômicas (participação no mundo industrializado e reforço no potencial tecnológico).

Cachapuz et al. (2011) também reconhecem a necessidade da alfabetização científica como parte da educação geral voltada a todos os cidadãos com vistas a possibilitar a participação nos processos de tomada de decisão. Indicam a necessidade de recuperar aspectos históricos da ciência, destacando a relação entre ciência, tecnologia, sociedade e ambiente. Postas tais considerações, entendemos que o objetivo da AC é formar cidadãos, e não preparar futuros especialistas; para tanto, é necessária a imersão dos estudantes em uma cultura científica, o que supera o ensino focado em aspectos estrita e exclusivamente conceituais.

Nessa perspectiva, destacamos Chassot (2014, p. 62), que conceitua alfabetização científica como "o conjunto de conhecimentos que facilitariam aos homens e mulheres fazer uma leitura do mundo onde vivem", com vistas à sua transformação: "seria desejável que os alfabetizados cientificamente não apenas tivessem facilitada a leitura do mundo em que vivem, mas entendessem as necessidades de transformá-lo, e transformá-lo para 
melhor". Mas o que seria um mundo melhor? Sob qual perspectiva deve-se considerar que a realidade está sendo transformada para melhor? Qual é a orientação dessa transformação?

Nesse ponto, é importante pensar que a alfabetização científica como objetivo educacional implica delinear, em última instância, um projeto de sociedade, conferindo uma orientação à participação social e à transformação. Em nosso entendimento, a transformação deve estar atrelada a um projeto de inclusão e de democratização do acesso aos bens culturais e materiais da sociedade, de humanização das relações e da prevalência de valores ligados à justiça social em detrimento dos interesses mercadológicos. "Nesse sentido, quanto mais conhecer, criticamente, as condições concretas, objectivas, de seu aqui e de seu agora, de sua realidade, mais poderá realizar a busca, mediante a transformação da realidade" (FREIRE, 1974, p. 12). A AC, a nosso ver, deve possibilitar a ampliação do conhecimento de mundo, levando o sujeito a perceber-se como ser de opções com vistas à superação das condições de opressão a que se encontra submetido.

Sasseron e Carvalho (2011, p. 61), em revisão bibliográfica sobre o conceito de alfabetização científica, consideram que "a alfabetização deve desenvolver em uma pessoa a capacidade de organizar seu pensamento de maneira lógica, além de auxiliar na construção de uma consciência mais crítica em relação ao mundo que a cerca”. Propõem a alfabetização científica como objetivo para a formação de cidadãos críticos com vistas à atuação na sociedade e organizam as habilidades implicadas nesse processo em três grupos, denominados eixos estruturantes da alfabetização científica, sendo eles: 1. Compreensão básica de termos, conhecimentos e conceitos científicos fundamentais; 2. Compreensão da natureza das ciências e dos fatores éticos e políticos que circundam sua prática; 3. Entendimento das relações existentes entre ciência, tecnologia, sociedade e meio ambiente.

Conforme observado, os diferentes autores, ao defenderem a perspectiva da alfabetização científica como objetivo do ensino de ciências, fazem-no sob múltiplas vertentes e compreensões do termo, ainda que pontos de aproximação possam ser visualizados. Pretende-se superar um modelo de ensino-aprendizagem pautado na transmissão dos produtos da ciência, em desconexão com os problemas complexos da realidade e em desacordo com a própria natureza do conhecimento científico (por cujo processo de produção perpassam fatores históricos, sociais e políticos, entre outros). Elucida-se a insatisfação com uma proposta de ensino voltada à formação de cientistas, ou à preparação para a escolaridade futura, objetivos que também não são alcançados por meio de um ensino que se reduz aos aspectos conceituais (CACHAPUZ et al., 2011). Em discussões atuais sobre alfabetização científica, emergem termos como cidadania, participação social, compreensão pública da ciência, indicando as relações que se estabelecem entre ciência, tecnologia e sociedade, e a necessidade de formar indivíduos cientificamente alfabetizados, capazes de compreender e intervir no debate público.

Os autores destacados discutem alfabetização científica a partir do enfoque da escola, propondo reflexões que dialogam especialmente com os contextos de educação formal. Neste artigo, indicamos a importância de espaços de educação não formal nesse processo, seja de maneira complementar ao sistema educativo formal, seja como espaço de educação ao longo da vida e de divulgação científica (PÉREZ; MOLINÍ, 2004), o que não significa negar o papel da escolarização na promoção da AC da população. 
Conforme exposto, delimitamos nossa compreensão de AC em diálogo com os autores apresentados e de modo a contemplar também a criança. Entendemos a AC como processo que ocorre dentro e fora da escola e que implica: i) a promoção de diálogos e aproximações entre a cultura experiencial ${ }^{3}$ dos indivíduos e a cultura científica ${ }^{4}$; ii) a apropriação de saberes relacionados a termos e conceitos científicos, à natureza da ciência, às relações entre ciência, tecnologia e sociedade; iii) a promoção de condições necessárias à realização de leituras críticas da realidade, à participação no debate público, à tomada de decisão responsável, à intervenção social em uma perspectiva emancipadora e de inclusão social; bem como que a AC deve promover não apenas a apropriação de conhecimentos, mas também a construção do que Freire chama de consciência epistemológica, potencializando a participação social. Pautamo-nos também na consideração da não neutralidade do ato pedagógico, o que nos obriga a delimitar os valores que perpassam as escolhas efetuadas. Em nosso caso, defendemos que as ações que visem à AC devam estar permeadas por um projeto emancipador e de inclusão social, em uma perspectiva de defesa do ser humano, da justiça social e da democracia.

Essa compreensão é sintetizada no quadro a seguir.

Figura 1: Esquema do conceito de AC.

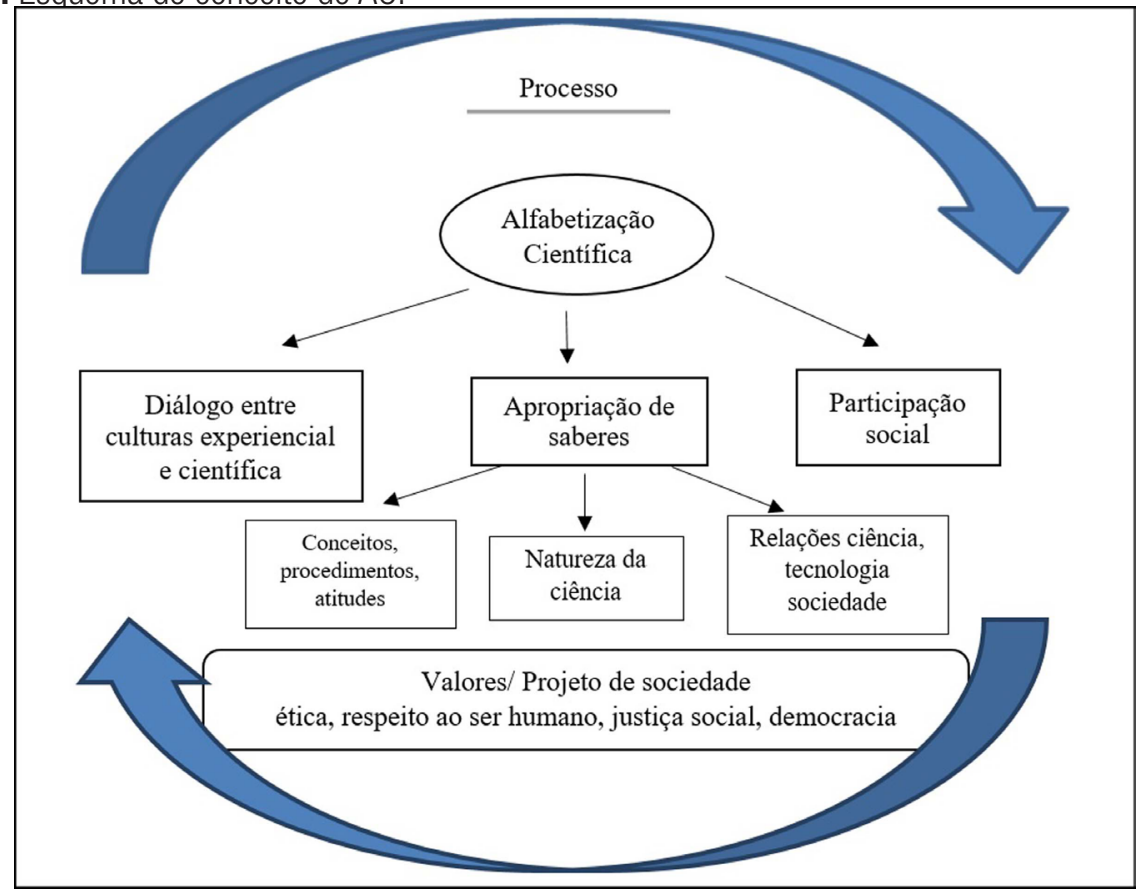

Fonte: autoria própria.

3- Entendida como "a plataforma cognitiva, afetiva e comportamental sobre a qual se assentam suas interpretações acerca da realidade, seus projetos de intervenção nela, seus hábitos essenciais e seus comportamentos cotidianos" (PÉREZ GÓMEZ, 2001, p. 205), gerada ao longo da experiência biográfica do indivíduo e estreitamente vinculada ao contexto.

4- Por cultura científica entende-se o conjunto de conceitos, procedimentos, normas e valores relacionadas ao campo científico, que se caracteriza por construir uma forma particular de ler a realidade, ancorada em linguagem e epistemologia próprias que são histórica e socialmente produzidas, configurando-se como produto cultural, empreendimento humano e prática social. 
Como exposto, é importante compreender a AC em diálogo com uma concepção de educação, de ciência e de sociedade, definindo-a em relação a um projeto formativo. Em nosso caso, depreendemos que os objetivos elucidados pelos autores ao apresentarem suas definições de AC são válidos, mas é necessário delimitar de maneira mais enfática o projeto de formação humana que os perpassa. Quer dizer, para nós, a AC justifica-se como condição necessária, ainda que insuficiente, à inserção crítica dos sujeitos na sociedade, devendo possibilitar-lhes a ampliação de sua leitura de mundo, a análise das informações que circulam na sociedade, a participação ativa nos debates e, em última instância, a intervenção social. Essa intervenção deve ocorrer fundada em uma perspectiva ética, na lógica da proteção ao ser humano, da busca de justiça social e de consolidação da democracia. Visa-se, dessa forma, à superação da lógica individualista e mercadológica, pautada nos interesses de grupos em detrimento do bem comum.

Findamos neste momento a discussão sobre o conceito de AC para tratar do sujeito da alfabetização científıca: a criança pode ser alfabetizada cientificamente? Ela já vivencia um processo de alfabetização científica? Apresentaremos essa discussão na próxima seção.

\section{Alfabetização científica e criança: algumas aproximações}

Com o objetivo de identificar produções atuais sobre AC e criança, realizamos pesquisa bibliográfica em periódicos da área ${ }^{5}$. Pesquisamos os periódicos indexados como Qualis A nas áreas de Ensino e Educação (Avaliação Capes 2014), cruzando com busca no Portal de Periódicos Capes e na base Scielo abrangendo as publicações de 2011 a 2016. Os termos de busca utilizados foram alfabetização cientifica e criança e seus correlatos em inglês e espanhol, procedendo-se a uma leitura de títulos e resumos com vistas a identificar se o artigo fazia referência à criança em idade pré-escolar e ao processo de AC. A inclusão inicial do termo educação não formal, em adição aos dois anteriores, mostrou-se infrutífera, o que nos levou a excluí-lo dessa etapa. Na pesquisa inicial, foram encontrados apenas dois artigos que tratavam explicitamente da questão, sendo um deles um relato de experiência (AMELOTTI et al., 2016) e outro uma pesquisa cujo foco é a formação de professores para o trabalho com AC na educação infantil (SMITH; LOUGHARAN; DIMITRAKOPOULOS, 2012). Ainda que possam ser encontradas produções que discutam ensino de ciência ou educação científica na educação infantil, optamos por não incluí-las na busca, visto que o foco é pensar a AC e a especificidade desse conceito em sua aproximação às discussões sobre criança e infância.

Diante do cenário, optamos por incluir artigos que tratassem da AC no contexto do primeiro ciclo do ensino fundamental. Consideramos que trabalhos com esse foco podem nos auxiliar na reflexão sobre AC e criança, uma vez que dialogam com as especificidades desse público. Quanto às interações entre AC, criança e ENF, optamos por discuti-las em seção posterior, recuperando trabalhos que dialogassem com as especificidades de ações de divulgação científıca para crianças, ainda que não tratem diretamente de alfabetização científica.

5- Pesquisa realizada em março de 2016. 
Por se tratar de temática ainda pouco explorada, conforme explicitado nos parágrafos anteriores, dedicamos esta seção à discussão sobre AC e criança, apresentando autores que discutem o tema (ainda que o façam no âmbito do ensino fundamental) e concepções de criança e infância com vistas a ampliar ou a ressignificar a concepção de AC quando falamos em crianças pequenas.

No Brasil, Lorenzetti e Delizoicov (2001, p. 1), em artigo bastante citado em pesquisas posteriores, apresentam uma discussão sobre AC no contexto das séries iniciais, entendendo-a como "atividade vitalícia, sendo sistematizada no espaço escolar, mas transcendendo suas dimensões para os espaços educativos não formais, permeados pelas diferentes mídias e linguagens”. Os autores partem da premissa de que é possível desenvolver a alfabetização científica nos anos iniciais do ensino fundamental (que, à época da publicação do artigo, atendia a crianças de 7 a 10 anos), independentemente do domínio da escrita alfabética. Quer dizer, os autores contrapõem-se à ideia de que a AC depende da apropriação prévia da escrita alfabética, o que excluiria desse processo as crianças que não dominam o código. Defendem que a AC deve ser compreendida "como o processo pelo qual a linguagem das Ciências Naturais adquire significados, constituindo-se um meio para o indivíduo ampliar o seu universo de conhecimento, a sua cultura, como cidadão inserido na sociedade" (LORENZETTI; DELIZOICOV, 2001, p. 8).

Ainda no contexto dos anos iniciais do ensino fundamental, podemos citar outras produções que discutem AC, como as de Brandi e Gurgel (2002), Viecheneski e Carletto (2013), Pizarro e Lopes Junior (2015), Sasseron (2008), entre outras. Em alguns casos, a alfabetização científica apresenta-se vinculada ao processo de aprendizagem da leitura e da escrita da língua portuguesa (BRANDI; GURGEL, 2002; VIECHENESKI; CARLETTO, 2013), concepção que, por um lado, pode significar a superação da fragmentação do conhecimento, mas que, por outro, pode reduzir a especificidade do processo de AC e colocá-lo a serviço da apropriação do código alfabético.

No que toca especificamente ao contexto da educação infantil (que abrange a faixa etária que nos interessa nesta pesquisa, ou seja, crianças de 0 a 5 anos), é possível identificar certa tensão no campo. Historicamente, a creche se constituiu como espaço de guarda e cuidado da criança de 0 a 3 anos, possibilitando a inserção da mulher no mercado de trabalho; a pré-escola, por sua vez, vinculou-se à preparação para a escolaridade subsequente, organizando-se de acordo com o modelo da escola primária, à luz de uma pedagogia denominada tradicional. É com a Lei 9.394/96 que, ao menos formalmente, tem-se a reconstrução desse cenário, buscando-se a superação da cisão via reconhecimento da educação infantil como primeira etapa da educação básica, etapa dotada de características próprias nas quais cuidado e educação devem estar articulados. Mudanças nas concepções de criança e de infância também contribuem para que seja revista a proposta pedagógica da educação infantil, superando-se o modelo de preparação para o ensino fundamental e considerando-se a importância de valorizar a infância e seus modos próprios de ser e estar no mundo, bem como a criança como produtora de cultura. Nesse contexto, a construção de uma proposta pedagógica para a educação infantil que considere a criança e as infâncias como centro do processo e promova a superação de uma pedagogia tradicional que tem como foco a transmissão de conteúdos fragmentados, por vezes, acaba por significar o 
esvaziamento do debate acerca do trabalho com o conhecimento: não podemos falar em alfabetização científica na educação infantil, já que isso pode representar o retorno a um modelo dito escolarizante que se quer superar.

Defendemos que incluir a criança no processo de AC não significa aderir a abordagens transmissivas, disciplinares e preparatórias para a escolaridade subsequente. Os conhecimentos do campo científico podem estar presentes nas experiências de aprendizagem possibilitadas às crianças de maneira integrada, participativa e lúdica, como um elemento da cultura mais ampla na qual a criança se insere. Faz-se necessário, portanto, considerar as especificidades da criança pequena, considerando suas formas próprias de pensar, interagir, ser e estar no mundo, suas lógicas (nas quais fantasia e realidade se fazem presentes de maneira não contraditória) e suas necessidades (que vão além da cognição). Construir propostas integradoras, pautadas na brincadeira e na interação, é condição necessária à promoção de processos de AC que, de fato, tomem a criança como sujeito, e não como objeto. Nessa linha, entendemos que a aproximação entre a cultura da criança e a científica pode se dar a qualquer momento de seu desenvolvimento.

Mas de que criança falamos, afınal? Historicamente, as crianças foram marginalizadas nos estudos sociológicos, assumindo uma posição subordinada na sociedade, concebidas exclusivamente como vir-a-ser, adultos em potencial (CORSARO, 2011). Perspectivas teóricas interpretativas e construtivistas lançam luzes para a infância como construção social, considerando que "as crianças, assim como os adultos, são participantes ativos na construção social da infância e na reprodução interpretativa de sua cultura compartilhada" (CORSAR0, 2011, p. 19), e não apenas espectadoras passivas e receptoras da produção do adulto. Nesse contexto, emerge uma criança ativa, partícipe, produtora de cultura, inserida em um contexto social no qual a infância pode ser vivenciada de diferentes maneiras, a depender das representações feitas sobre ela e das condições concretas de existência. ${ }^{6}$ As crianças participam ativamente da sociedade mediante um processo de reprodução interpretativa, em que criam culturas de pares à medida que selecionam ou se apropriam criativamente de informações do mundo adulto, ressignificando-as. Nesse sentido, "as crianças não se limitam a internalizar a sociedade e a cultura, mas contribuem ativamente para a produção e mudança culturais" (CORSAR0, 2011, p. 31-32), sendo simultaneamente afetadas pelas sociedades e culturas que integram.

A perspectiva elucidada ajuda-nos a compreender as crianças como produtoras de cultura, alimentadas pela participação em culturas de pares que, por sua vez, recebem influência de diversos campos institucionais (família, escola, religião, política etc.). Quer dizer, as crianças participam dos campos culturais, o que inclui a cultura científica: ao se inserirem em um mundo com ciência e tecnologia, apropriam-se criativamente de seus elementos, fazendo-se necessário que se reconheça o direito a essa participação. Trata-se de considerar também a criança como sujeito do processo de AC, que, como mencionado, pode ser fomentado por diversas instâncias, e não apenas pela escola. Nesse sentido:

6- As crianças são os sujeitos que se situam na infância, esta entendida como categoria social de tipo geracional; as crianças crescem, mas a infância permanece na sociedade. 
0 mundo material e simbólico se oferece à criança através das pessoas, da cultura, dos alimentos, da natureza e é certo que ela o incorpora. Porém, a criança não o compreende a partir da lógica adulta, pois com ele se relaciona de modo particular. As crianças, em suas brincadeiras, em seus modos de falar, comer, andar, desenhar, não apenas se apropriam com o corpo, a mente e a emoção daquilo que as suas culturas lhes propiciam, mas investigam e questionam criando, a partir das tradições recebidas, novas contribuições para as culturas existentes. (BARBOSA, 2009, p. 15).

Em novo esforço de sintese, delineamos três compreensões que se complementam na defınição de alfabetização científica e que justificam a importância de pensá-la também para a criança:

1. Alfabetização científica como processo que ocorre na escola e fora dela, desde o início da inserção da criança no mundo, repleto de produções da ciência e da tecnologia.

2. AC como objetivo formativo, que visa à apropriação de elementos da ciência para compreender o contexto social e participar ativa e criticamente dos processos decisórios.

3. AC como direito de todos: direito à educação, à cultura, ao conhecimento, à compreensão da realidade em que nos inserimos, à construção de novas leituras de mundo.

Consideramos que o esquema-síntese do conceito de AC, apresentado na seção anterior, permite-nos incluir a criança no processo, sem negar as especificidades que a caracterizam. Para a criança pequena, estar em processo de AC não implica necessariamente apropriar-se de termos e conceitos científicos, ainda que isso possa ocorrer. Estar em contato com o conhecimento científico por meio de uma visita ao zoológico ou a uma exposição, cuidando de pequenos animais na escola, observando o caminho da formiga que carrega uma folha e visualizando representações do corpo humano em uma enciclopédia já significa vivenciar o processo de AC, aproximando-se de elementos da cultura científica. Envolver-se em questionamentos sobre fenômenos que ocorrem à sua volta, elaborar hipóteses, buscar informações, socializar com outras crianças suas impressões significa aproximar-se de reflexões sobre a natureza da ciência.

Nesse aspecto, a relação entre criança e AC implica, primeiramente, colocar a criança como ponto de partida, fazendo-se necessário que as ações propostas pautem-se na brincadeira e nas interações. Em segundo lugar, implica considerar que as relações entre criança e AC devem ser estabelecidas em termos de grau, e não de polarizações: não se trata de excluí-la desse objetivo formativo e desse direito, tampouco de exigir que se aproprie de infindáveis termos científicos sem significado, preparando-a para a etapa subsequente de escolaridade, mas sim de não lhe negar o acesso a elementos da cultura científica, possibilitando a ampliação de suas experiências de aprendizagem para além de suas vivências cotidianas (aproximando sua cultura experiencial à cultura científica, como apontamos na seção anterior). 0 direito da criança à AC não pode representar a negação do direito à vivência da(s) infância(s); a aproximação à cultura científica não significa a supressão das culturas da(s) infância(s), mas a ampliação destas. 
Cabe destacar que as produções citadas tratam da educação formal, indicando o papel da escola na promoção da AC. Resta-nos discutir o papel dos espaços de educação não formal nesse processo.

\section{Espaços da alfabetização científica: a educação não formal}

Na seção anterior, defendemos que a consideração da AC como processo que ocorre dentro e fora da escola implica a imersão na cultura científica em suas relações com o contexto social mais amplo, permitindo-nos afırmar que as crianças vivenciam, sim, esse processo pelo simples fato de existirem e estarem inseridas em uma sociedade permeada por produtos da ciência e da tecnologia. De fato, há aprendizagens que ocorrem de maneira informal, por meio da participação em práticas sociais, como ir ao posto de saúde tomar vacina, ouvir comentários sobre a situação climática e a passagem do dia - "hoje vai chover"; "chegou uma frente fria"; "está anoitecendo mais cedo" -, acompanhar os familiares ao mercado ou à feira etc. As crianças, desde cedo, vão se apropriando de conhecimentos sobre o mundo natural e a tecnologia, mas de maneira assistemática, fragmentada, ocasional, e as aprendizagens serão mais ou menos potencializadas em função do ambiente e de suas possibilidades. Nesse caso, falamos de processos de educação informal (LIBÂNEO, 1994).

As crianças podem também se apropriar de conhecimentos e exercitar a problematização, a argumentação e o pensamento reflexivo por meio de contextos e ações pautados em objetivos definidos conscientemente, ao que chamamos de educação intencional (LIBÂNEO, 1994). Nesse contexto, podemos falar de educação formal (escolar) - entendida como "o sistema educativo altamente institucionalizado, cronologicamente graduado e hierarquicamente estruturado que se estende desde os primeiros anos da escola primária até os últimos anos da universidade" (PÉREZ; MOLINÍ, 2004, p. 4) - e em educação não formal (extraescolar) - compreendida como "toda atividade organizada, sistemática, educativa, realizada fora do marco do sistema oficial, para facilitar certos tipos de aprendizagem a subgrupos particulares da população, tanto adultos como crianças" (PÉREZ; MOLINÍ, 2004, p. 4).

Segundo Trilla et al. (2003, p. 11), a educação não formal "se refere a todas aquelas instituições, atividades, meios, âmbitos da educação que, não sendo escolares, foram criados expressamente para satisfazer determinados objetivos educativos”. Trata-se de um tipo de educação intencional, metódica, com objetivos definidos, mas não circunscrita à escolaridade convencional. Segundo os autores, o setor educativo não formal mostra-se disperso e heterogêneo, abarcando desde brinquedotecas a programas de alfabetização não escolar. Trilla et al. (2003) destacam a impossibilidade de se atribuir à escola o monopólio da educação. Nesse sentido, o conceito de educação não formal pressupõe uma concepção ampliada de educação, entendida como processo que se situa em diferentes espaços e tempos, "fenômeno complexo, multiforme, disperso, heterogêneo, permanente e quase onipresente” (TRILLA, 2008, p. 29). Pautado no critério estrutural7 , Trilla (2008, p. 42)

7- 0 critério estrutural distingue educação formal e não formal por sua inclusão ou não no sistema educativo regrado: formal é aquilo que é assim definido em termos administrativos e legais; e não formal é o que permanece à margem do organograma do sistema educacional. A educação informal, por sua vez, é aquela que ocorre indiferenciada e subordinadamente a outros processos sociais, de maneira difusa. 
conceitua educação não formal (ENF) como "o conjunto de processos, meios e instituições específica e diferenciadamente concebidos em função de objetivos explícitos de formação ou instrução não diretamente voltados à outorga dos graus próprios do sistema educacional regrado". Seus âmbitos de atuação são bastante amplos e heterogêneos, o que permite abarcar uma série de intencionalidades e públicos (TRILLA et al., 2003).

Para Gohn (2014, p. 40), a ENF “designa um conjunto de práticas socioculturais de aprendizagem e produção de saberes, que envolve organizações/ instituições, atividades, meios e formas variadas, assim como uma multiplicidade de programas e projetos sociais”. A autora afirma, ainda, que os aprendizados possibilitados pela ENF não são espontâneos, uma vez que "os processos que o produzem têm intencionalidades e propostas" (GOHN, 2014, p. 40).

Os termos educação formal, não formal e informal são explorados de diferentes maneiras na literatura e mesmo nas práticas educativas concretas. Como aponta Smith (1996), grande parte das definições é limitada e não colabora com a compreensão das diferenças e semelhanças entre essas modalidades, uma vez que se pauta na dimensão física do espaço escolar - fora ou dentro da escola. Além disso, constatam-se, muitas vezes, sobreposições quando se deseja, por exemplo, categorizar uma dada ação ou prática educativa como formal, não formal ou informal. Nessa linha, Rogers (2004) sugere que tais modalidades educativas devem ser vistas como um continuum e não como categorias estanques. Com base nessa perspectiva, Marandino et al. (2008) propõem que se supere a ideia de separação e fragmentação entre esses espaços. Por exemplo, pode-se considerar um museu um espaço de ENF do ponto de vista institucional, mas, sob o olhar do público, ele pode se configurar como educação formal (quando os alunos o visitam para uma atividade altamente estruturada pela escola), ou mesmo como educação informal (considerando um visitante que procura o museu para se divertir). É relevante, assim, especificar quem são os agentes e os sujeitos da ação educativa para caracterizá-la.

Os aspectos discutidos anteriormente revelam a complexidade que perpassa a definição dos termos. Consideramos, contudo, que a ENF é uma prática sociocultural intencional de aprendizagem e de produção de saberes, não vinculada ao sistema educacional regrado e que ocorre em diferentes espaços sociais. Aqui, é importante que voltemos à nossa questão inicial: qual pode ser a contribuição da ENF no processo de AC de crianças?

Para responder a essa questão, é necessário inicialmente sublinhar a existência e a relevância das experiências educativas não formais existentes hoje, com foco nas ciências naturais e voltadas às crianças. No Brasil, encontramos um enorme e variado número de experiências dessa natureza: numa consulta ao sítio da $13^{\text {a }}$ Semana Nacional de Ciência e Tecnologia (SNCT), de $2016^{8}$, das 1.391 atividades cadastradas no universo de 361 cidades e 1.491 instituições, 126 delas têm as crianças como público-alvo. Destacamos que as atividades das SNCT, criadas em 2004, são organizadas por universidades e instituições de pesquisa; escolas públicas e privadas; institutos de ensino tecnológico, centros e museus de C\&T; entidades científicas e tecnológicas; fundações de apoio à

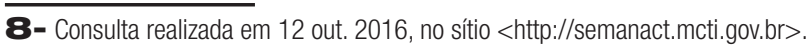


pesquisa; parques ambientais, unidades de conservação, jardins botânicos e zoológicos; secretarias estaduais e municipais de C\&T e de educação; empresas públicas e privadas; meios de comunicação; órgãos governamentais; ONGs e outras entidades da sociedade civil voltadas para os mais variados públicos, sendo que as crianças vêm ocupando um interessante espaço nesse universo.

Com relação às instituições com foco na educação não formal e na divulgação da ciência no país, encontramos, de acordo com o Guia de Centros e Museus do Brasil de 2009, 190 espaços de popularização de ciência cadastrados e espalhados pelo país, como museus, zoológicos, aquários, planetários, observatórios e jardins botânicos, os quais mantêm uma programação variada para todas as faixas etárias, incluindo as crianças.

Identificamos, desse modo, a existência de ações, programas e instituições de educação não formal que, assimilados como espaços de educação ao longo da vida e de divulgação científica, possuem um enorme potencial de promover o processo de alfabetização científica também das crianças. Como já afirmamos, do ponto de vista teórico, a AC deve ser entendida como processo, objetivo formativo e direito, considerando a criança como sujeito da AC. Nesta seção, portanto, defendemos a importância dos espaços de ENF no processo educativo e, como consequência, na promoção da AC, incorporando a criança como partícipe.

Para além disso, no que se refere às potencialidades de espaços de ENF na promoção de ações de divulgação científica para crianças, Neves e Massarani (2016) indicam a missão cultural de museus e centros de ciência na inclusão da criança. Carvalho e Lopes (2016), por seu turno, defendem a garantia do direito de acesso e atendimento de qualidade às crianças pequenas nos museus, destacando o potencial desses espaços na promoção de momentos lúdicos de aprendizagem significativa para o público infantil e a necessidade de planejar propostas educativas voltadas a esse segmento. Studart (2005, p. 66) atesta que "um espaço projetado exclusivamente para crianças e que desenvolve um tema central, conceitualmente conexo e de interesse para elas, tem impacto mais positivo sobre o aprendizado, as emoções e a experiência infantil".

Em específico, Iszlaji (2012) analisa em que medida os museus de ciência atendem a crianças pequenas em suas ações, com destaque para as exposições. Afırma que os primeiros museus voltados ao público infantil foram criados na virada do século XIX inspirados especialmente nas teorias de Froebel, Pestalozzi, Dewey e Montessori - e destaca que "os museus das crianças são considerados espaço educativo, criativo e cultural, com o objetivo de engajar as crianças em experiências lúdicas que possibilitam a aprendizagem divertida e prazerosa" (ISZLAJI, 2012, p. 85). Informa que, à época da realização de sua pesquisa (2012), havia cerca de 500 museus das crianças no mundo, 400 deles nos Estados Unidos e nenhum no contexto brasileiro, ainda que fosse possível identificar museus que organizam exposições e/ou ações educativas voltadas ao público infantil.

Por meio de questionário endereçado aos setores educativos de 110 museus de ciência brasileiros, Iszlaji (2012) constatou, à época, que 74\% dos museus analisados desenvolviam exposições e ações educativas para o público infantil, mas apenas um museu de ciência mantinha uma exposição destinada à criança - o Museu de Ciência e Tecnologia da PUC/RS. Quanto aos desafios apontados pelas equipes no que respeita ao desenvolvimento 
de exposições para crianças, foram destacadas: a necessidade de adequação da linguagem; a dificuldade em relação à transposição didática; a elaboração de atividades e experimentos interativos adequados ao público infantil. A autora constatou que há uma preocupação dos museus brasileiros em atender ao público infantil, mas as ações nesse sentido concentram-se nas intervenções dos monitores, e não necessariamente na organização de exposições voltadas à criança. Quanto aos objetivos apontados pelas equipes, foram citados: "despertar a curiosidade, a experimentação e o interesse pela ciência e seus fenômenos de forma lúdica, provocativa e prazerosa", bem como "contribuir com a divulgação científica e a alfabetização científica para o público infantil” (ISZLAJI, 2012, p. 93).

Em síntese, considerar o potencial de espaços de ENF para a AC da criança implica construir propostas que tomem essa mesma criança e a infância como pontos de partida. Como aponta Iszlaji (2012), o fato de uma exposição, por exemplo, levar em consideração aspectos voltados à criança pequena - como a dimensão física (que inclui o tamanho do mobiliário), a diversidade de atividades, o estímulo à liberdade e à autonomia da criança na sua escolha dos aparatos e a interação entre as crianças, sem necessariamente a mediação do adulto - reforça a percepção de que a forma de organizar o espaço interfere significativamente no desenvolvimento e na aprendizagem infantis. Consideramos que valorizar a brincadeira, as formas de expressão infantis, as múltiplas linguagens, a interação, a participação, a possibilidade de escolha, o desafıo, a fantasia e a curiosidade mostra-se essencial à construção de propostas que incluam a criança pequena em espaços de ENF.

\section{Considerações finais}

Em vias de finalização e com vistas a responder à questão proposta no início deste artigo, sistematizamos a seguir os argumentos apresentados ao longo do texto.

Perguntamos: Do ponto de vista conceitual, quais inter-relações podem ser estabelecidas entre alfabetização científica, criança e educação não formal? Entendendo a AC como processo e como direito, e a criança como sujeito de direitos, defendemos sua inclusão nesse processo. Partindo de um marco conceitual que considera a criança como agente, produtora de cultura e partícipe, superando a concepção de criança como ser incapaz e incompleto, passamos a considerá-la como sujeito do processo educativo. A compreensão da AC como objetivo formativo a ser assumido por diferentes instâncias educacionais implica considerar o papel de espaços de ENF na promoção do processo de $\mathrm{AC}$, dentro das especificidades que os caracterizam e os diferenciam da instituição escolar. A efetiva inclusão da criança em ações educativas proporcionadas por espaços de ENF demanda a configuração destes de modo a dialogar com as culturas da infância, o que envolve a adequação de tempos e espaços, a presença de múltiplas linguagens, da dimensão lúdica, do imaginário e da interação.

Perguntamos, ainda: Quando começa o processo de alfabetização científica? Podemos incluir a criança pequena nesse processo? Quais implicações decorrem da consideração da criança como sujeito do processo de alfabetização científica? A AC tem início no momento em que nascemos e nos inserimos na cultura, o que inclui a presença de elementos da cultura científica nas experiências mais iniciais da relação do ser humano 
com o mundo. Nesse sentido, a compreensão de alfabetização vai além da capacidade de ler a palavra; requer ler o mundo, do que decorre a possibilidade de considerarmos a criança pequena também como sujeito desse processo. Afirmamos, assim, que defender que a criança pequena pode ser sujeito da alfabetização científica demanda, inicialmente, situar o conceito de AC em sua dimensão processual, ressignificando-o de maneira a contemplar a criança em suas formas próprias de ser e estar no mundo, isto é, em termos de aproximação das culturas infantis a elementos da cultura científica, tendo o brincar como linguagem privilegiada da(s) infância(s).

Podemos pensar na educação não formal como espaço para a alfabetização científıca? Ao assumir a concepção de AC como processo que ocorre dentro e fora da escola, destacamos a importância de espaços de ENF na promoção da AC, o que demanda organizar ações com vistas a esse objetivo, de modo a incluir a criança. Tomar a criança como público significa pensar, no interior das instituições não formais, processos de formação dos profissionais, desenvolvimento de ações, configurações de espaços e de tempos, elaboração de produtos especialmente voltados a ela. Significa promover a efetiva articulação entre a cultura da infância e a cultura científica, o que entendemos ser um enorme e produtivo desafio.

A AC, então, vem ganhando espaço no campo das pesquisas, incluindo aquelas que se debruçam sobre a ENF. 0 que precisamos neste momento defender é a necessidade de incorporar a essas discussões a criança pequena, o que significa considerar seus modos próprios de ser e estar no mundo. As interfaces possíveis entre AC, criança e ENF aqui delineadas partem de concepções específicas de cada um desses conceitos, fundadas em um projeto de democratização do acesso ao conhecimento e à cultura como condição de inserção crítica na sociedade. E, se falamos em democratização e abertura de possibilidades, faz-se necessário pensar também na criança e em seu direito de vivenciar experiências nas quais os conhecimentos científicos estejam presentes. Assim, é relevante fomentar o acesso a esses saberes, promovendo a interlocução entre as culturas da infância e elementos da cultura científica. Para tal, cabe destacarmos a importância do lúdico e, especificamente, da brincadeira como linguagem privilegiada da criança, bem como a importância das interações no processo de apropriação do mundo à sua volta.

\section{Referências}

AMELOTTI, Ivana et al. Alfabetización científica en el ámbito preescolar: primeros conocimientos como herramientas para la promoción de la salud y la prevención de la Enfermedad de Chagas. Revista Eureka sobre Ensenanza y Divulgación de las Ciencias, Cádiz, v. 13, n. 1, p. 192-202, 2016.

BARBOSA, Maria Carmen S. (Consult.). Práticas cotidianas na educação infantil: bases para a reflexão sobre as orientações curriculares. Projeto de cooperação técnica MEC e UFRGS para construção de orientações curriculares para a educação infantil. Brasília, DF: MEC/SEB/UFRS, 2009.

BRANDI, Arlete Terezinha E.; GURGEL, Celia Margutti A. A alfabetização científica e o processo de ler e escrever em séries iniciais: emergências de um estudo de investigação-ação. Ciência \& Educação, Bauru, v. 8, n. 1, p. 113-125, 2002. 
BYBEE, Rodger W. Achieving scientific literacy. The Science Teacher, Arlington, v. 62, n. 7, p. 28-33, 1995.

CACHAPUZ, António et al. A necessária renovação do ensino das ciências. São Paulo: Cortez, 2011.

CARVALHO, Cristina; LOPES, Thamiris. 0 público infantil nos museus. Educação e Realidade, Porto Alegre, v. 41, n. 3, p. 911-930, jul./set. 2016.

CHASSOT, Attico. Alfabetização científica: questões e desafios para a educação. 6. ed. ljuí: Unijuí, 2014.

CORSARO, William A. Sociologia da infância. Porto Alegre: Artmed, 2011.

DAZA-CAICEDO, Sandra. La apropiación social de la ciencia y la tecnología como un objeto de frontera. In: VOGT, Carlos et al. (Ed.). Comunicação, divulgação e percepção pública de ciência e tecnologia. Rio de Janeiro: De Petrus, 2013. p. 49-62.

FOUREZ, Gérard. Crise no ensino de ciências? Investigações em Ensino de Ciências, Porto Alegre, v. 8, n. 2, p. 109-123, 2003.

FREIRE, Paulo. A importância do ato de ler: em três artigos que se completam. Campinas: Autores Associados; São Paulo: Cortez, 1988.

FREIRE, Paulo. Papel da educação na humanização. In: FREIRE, Paulo. Uma educação para a liberdade. Porto: Textos Marginais, 1974.

FREIRE, Paulo. Pedagogia da autonomia: saberes necessários à prática educativa. 27. ed. Rio de Janeiro: Paz e Terra, 1996.

GARFIELD, Eugene. Science literacy. Part 1: What is science literacy and why is it important? In: GARFIELD, Eugene. Essays of an information scientist: science literacy, policy, evaluation, and other essays. v. 11. Philadelphia: ISI Press, 1988. p. 251-257.

GIL, Antônio Carlos. Como elaborar projetos de pesquisa. 4. ed. São Paulo: Atlas, 2002.

GOHN, Maria da Glória. Educação não formal, aprendizagens e saberes em processos participativos. Investigar em Educação, Porto, v. 1, p. 35-50, 2014.

HENRIKSEN, Ellen; FROYLAND, Merethe. The contribution of museums to scientific literacy: views from audience and museum professionals. Public Understanding of Science, v. 9, n. 4, p. 393-415, out. 2000.

INSTITUTO ABRAMUNDO. ILC - Indicador de Letramento Científico: sumário executivo de resultados. São Paulo: Instituto Abramundo, 2014.

ISZLAJI, Cynthia. A criança nos museus de ciências: análise da exposição Mundo da Criança do Museu de Ciência e Tecnologia da PUCRS. 2012. 256 f. Dissertação (Mestrado em Ensino de Ciências) - Faculdade de Educação, Instituto de Física, Instituto de Química e Instituto de Biociências da Universidade de São Paulo, São Paulo, 2012. 
JENKINS, Edgar W. Scientific literacy. In: HUSEN, Torsten; POSTLETHWAITE, T. Neville (Ed.). The international encyclopedia of education. v. 9. Oxford: Pergamon, 1994. p. 5345-5350.

JENKS, Chris. Constituindo a criança. Educação, Sociedade e Culturas, Porto, n. 17, p. 185-216, 2002.

KRASILCHIK, Myriam; MARANDINO, Martha. Ensino de ciências e cidadania. São Paulo: Moderna, 2007.

LAUGKSCH, Rudi C. Scientific literacy: a conceptual overview. Science Education, Hoboken, v. 84, n. 1, p. 71-94, 2000.

LEWENSTEIN, Brusse; BROSSARD, Dominique. Assessing models of public understanding in ELSI outreach materials, USA: Department of Energy: Cornell: Cornell University, 2006. Final report.

LIBÂNEO, José Carlos. Didática. São Paulo: Cortez, 1994.

LORENZETTI, Leonir; DELIZOICOV, Demétrio. Alfabetização científica no contexto das séries iniciais. Ensaio, Belo Horizonte, v. 3, n. 1, p. 1- 17, jun. 2001.

MARANDINO, Martha et al. Educação em museus: a mediação em foco. São Paulo: Geenf/Feusp, 2008.

MILLER, Jon D. The measurement of civic scientific literacy. Public Understand of Science, v. 7, n. 3, p. 203-223, 1998.

NEVES, Rosicler; MASSARANI, Luisa. 0 olhar das crianças sobre uma exposição interativa. In: MASSARANI, Luisa; NEVES, Rosicler; AMORIM, Luís (Org.). Divulgação científica e museus de ciências: 0 olhar do visitante - memórias do evento. Rio de Janeiro: Museu da Vida/Casa de Oswaldo Cruz/Fiocruz; RedPop, 2016. p. 65-72.

PÉREZ, Constancio A.; MOLINÍ, Ana María V. Consideraciones generales sobre la alfabetización científica em los museos de la ciencia como espacios educativos non formales. Revista Electrónica de Enseñanza de las Ciencias, Vigo, v. 3, n. 3, p.1-26, 2004.

PÉREZ GÓMEZ, Ángel I. A cultura escolar na sociedade neoliberal. Porto Alegre: Artmed, 2001.

PIZARRO, Mariana V.; LOPES JUNIOR, Jair. Indicadores de alfabetização científica: uma revisão bibliográfica sobre as diferentes habilidades que podem ser promovidas no ensino de ciências nos anos iniciais. Investigações em Ensino de Ciências, Porto Alegre, v. 20, n. 1, p. 208-238, 2015.

QVORTRUP, Jens. Childhood matters: an introduction. In: QVORTRUP, Jens et al. Childhood mattters: social theory, practices and politics. Aldershot: Avebury, 1994. p. 1-24.

ROBERTS, Douglas A. Scientific literacy/Science literacy. In: ABELL, Sandra K.; LEDERMAN, Norman G. Handbook of research in science teaching and learning. New York: McMillan, 2007. p. 729-780.

ROGERS, Alan. Looking again at non-formal and informal education: Towards a new paradigm. 2004. Disponivel em: <http://infed.org/mobi/looking-again-at-non-formal-and-informal-education-towards-anew-paradigm/>. Acesso em: set. 2007. 
SANTOS, Wildson Luiz P. Educação científica na perspectiva de letramento com prática social: funções, princípios e desafios. Revista Brasileira de Educação, Rio de Janeiro, v. 12, n. 36, p. 474-550, set./dez. 2007.

SARMENTO, Manuel Jacinto. Gerações e alteridade: interrogações a partir da sociologia da infância. Educação e Sociedade, Campinas, v. 26, n. 91, p. 361-378, maio/ago. 2005.

SASSERON, Lúcia Helena. Alfabetização científica no ensino fundamental: estrutura e indicadores deste processo em sala de aula. 2008. 265f. Tese (Doutorado em Educação) - Faculdade de Educação da Universidade de São Paulo, São Paulo, 2008.

SASSERON, Lúcia Helena; CARVALHO, Anna Maria P. Alfabetização científica: uma revisão bibliográfica. Investigações em Ensino de Ciências, Porto Alegre, v. 16, n. 1, p. 59-77, 2011.

SMITH, Kathleen V.; LOUGHARAN, Jeffrey; DIMITRAKOPOULOS, Cathy. Developing scientific literacy in a primary school. International Journal of Science Education, v. 34, n. 1, p. 127-152, Jan. 2012.

SMITH, Mark. What is non-formal education? The encyclopaedia of informal education. 1996. Disponível em: <http://infed.org/mobi/what-is-nonformal-education/>. Acesso em: set. 2007.

STUDART, Denise C. Museus e famílias: percepções e comportamentos de crianças e seus familiares em exposições para o público infantil. História, Ciências, Saúde, Manguinhos, v. 12 (suplemento), p. 55-77, 2005.

TRILLA, Jaume. A educação não-formal. In: ARANTES, Valéria A. (Org.) Educação formal e não-formal. São Paulo: Summus, 2008. p. 15-58. Pontos e contrapontos.

TRILLA, Jaume et al. La educación fuera de la escuela: ámbitos no formales y educación social. Barcelona: Ariel Educación, 2003.

VIECHENESKI, Juliana P.; CARLETTO, Marcia R. Iniciação à alfabetização científica nos anos iniciais: contribuições de uma sequência didática. Investigações em Ensino de Ciências, Porto Alegre, v. 18, n. 3, p. 525-543, 2013.

Recebido em: 20.10 .2016 Modificações em: 25.04.2017 Aprovado em: 05.07.2017

Amanda Cristina Teagno Lopes Marques é professora efetiva do Instituto Federal de Educação, Ciência e Tecnologia de São Paulo, com atuação nas licenciaturas e no Programa de Mestrado Profissional em Ensino de Ciências e Matemática. Possui doutorado em Educação pela Faculdade de Educação da Universidade de São Paulo (2011), com período sanduíche na Universidade de Bolonha (Itália).

Martha Marandino é professora associada da Faculdade de Educação da Universidade de São Paulo, coordenadora do Grupo de Estudos e Pesquisas em Educação Não Formal e Divulgação da Ciência (Geenf), bolsista de produtividade do CNPq, nível 1D, e livre-docente pela Universidade de São Paulo (2012). 